\title{
JUSTICIA Y \\ RESPONSABILIDAD \\ SOCIAL. \\ DERECHO Y DEBER \\ HUMANOS. \\ UNA UISIÓN DESDE \\ EL PENSAMIENTO DE \\ WALZER Y EJEMPLOS \\ DE LA DESIGUALDAD \\ EN MÉXICO
}

RUBÉN MENDOZA VALDÉS

Profesor-Investigador del Instituto de Estudios sobre

la Universidad (IESU), Universidad Autónoma del Estado de México

ELBA MARGARITA GONZÁLEZ FABIÁN

Universidad Autónoma del Estado de México

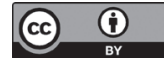




\title{
JUSTICIA Y RESPONSABILIDAD SOCIAL.* DERECHO Y DEBER HUMANOS. UNA VISIÓN DESDE EL PENSAMIENTO DE WALZER Y EJEMPLOS DE LA DESIGUALDAD EN MÉXICO
}

\begin{abstract}
Resumen: La justicia social, entendida como un modo de igualdad compleja, conlleva la necesidad inseparable del ejercicio de la responsabilidad social de las instituciones que representan las esferas de distribución de bienes, en tanto un deber. En ese sentido, Walzer considera que sólo en la medida en la que la distribución responda a los significados sociales, podrán cubrirse, en el marco de la igualdad, las necesidades de una sociedad en un ámbito de derechos comunitarios y deberes ciudadanos. Lo anterior representa un faro orientador para las políticas y responsabilidades de las instituciones y empresas de los países con enormes problemas de desigualdad social como es el caso de México.
\end{abstract}

Palabras clave: justicia, responsabilidad social, igualdad, derecho, deber.

\section{SOCIAL RESPONSIBILITY AND JUSTICE. HUMAN RIGHTS AND DUTIES. A VIEW FROM THE THOUGHT OF WALZER AND EXAMPLES OF INEOUALITY IN MEXICO}

\begin{abstract}
Social justice, understood as a way of complex equality, entails the need for exercise inseparable from the social responsibility of institutions that represent the areas of distribution of goods, as a duty. In that sense, Walzer believes that only to the extent that the distribution meets the social meanings, may be covered within the framework of equality, the needs of a society in a field of community rights and duties. This represents a guiding beacon for the policies and responsibilities of institutions and companies from countries with enormous problems of social inequality as the case of Mexico.
\end{abstract}

Keywords: justice, social responsibility, equality, rights, duties.

Fecha de recepción: julio 8 de 2015

Fecha de aceptación: mayo 9 de 2016

Forma de citar (APA): Mendoza, R. y González. E. (2016). Justicia y responsabilidad social. Derecho y deber humanos. Una visión desde el pensamiento de Walzer y ejemplos de la desigualdad en México. Revista Filosofía UIS, 15 (1), 61-88, doi: http://dx.doi.org/10.18273/revfil.v15n1-2016003

Forma de citar (Harvard): Mendoza, R. y González. E. (2016). Justicia y responsabilidad social. Derecho y deber humanos. Una visión desde el pensamiento de Walzer y ejemplos de la desigualdad en México. Revista Filosofía UIS, 15 (1), 61-88.

Rubén Mendoza Valdés: mexicano. Profesor-Investigador del Instituto de Estudios sobre la Universidad (IESU), Universidad Autónoma del Estado de México. Doctor en Humanidades: Ética, Universidad Autónoma del Estado de México.

Correo electrónico: mevr68@hotmail.com

Elba Margarita González Fabián: mexicana. Magister en Derecho, candidata a Doctora en Humanidades, Universidad Autónoma del Estado de México.

Correo electrónico: elmagofa@gmail.com

\footnotetext{
* Artículo de reflexión
}

Revista Filosofía UIS, Vol. 15, No. 1, enero-junio de 2016 pp. 61-88 
Justicia y responsabilidad social. Derecho y deber humanos. Una visión

\section{JUSTICIA Y RESPONSABILIDAD SOCIAL. DERECHO $Y$ DEBER HUMANOS. UNA VISIÓN DESDE EL PENSAMIENTO DE WALZER Y EJEMPLOS DE LA DESIGUALDAD EN MÉXICO}

\section{Introducción}

Pensar la justicia como un derecho humano implica profundizar su sentido amplio para llevarlo a flote en situaciones concretas, cuyas circunstancias se entiendan desde un tiempo y espacio propios. En el mismo tenor, tocar el punto de la responsabilidad social conduce a situarla en la perspectiva del deber. De esa forma, sólo podrá concretizarse el horizonte de la justicia sobre el plano de la responsabilidad de los seres humanos en comunidad. No hay justicia sin responsabilidad social.

En lo siguiente se intenta establecer una convergencia entre la justica como derecho humano y la responsabilidad social en tanto un deber; todo ello desde la propuesta filosófica de Michael Walzer. A la vez se analizan algunos casos relacionados con las acciones de las instituciones gubernamentales en México, posteriores a la Revolución mexicana, en los cuales podrá observarse que, bajo la visión de una igualdad simple, sólo han generado una mayor desigualdad.

El hilo conductor de la siguiente reflexión es el sentido de la justicia distributiva. Se inicia por establecer un planteamiento del problema el cual guiará el análisis de la investigación. A continuación se presenta un concepto de justicia que conlleva una relación con la igualdad, a su vez, ésta última se diferencia en simple y compleja. Lo anterior se conecta con la idea de sociedad y justicia distributiva. Finalmente, se aborda el asunto de la responsabilidad social pensada desde el móvil del deber. 
La idea central se inclina a pensar el modo en cómo las acciones de la política mexicana, las instituciones y empresas que la generan, podría asumir la justicia como un derecho humano a partir de la responsabilidad social en tanto un deber; todo ello en el sentido de velar por la dignidad de la especie y los grupos humanos, más allá de intereses individuales que, a larga, son la causas de los grandes problemas sociales, que tanto ricos y pobres tienen que padecer. Mirar como especie significa dignificar la vida de cada individuo.

\section{Planteamiento del problema}

La justicia es un derecho humano que se tiene que reconocer y la responsabilidad social un deber que requiere asumirse. En términos generales, para el asunto aquí tratado, se entenderá la justicia, en su sentido social, como el fenómeno humano que permite el orden e igualdad en los ámbitos individual y comunitario. Asimismo, la responsabilidad social significa el modo en el cual el ser humano asume las consecuencias de sus actos u omisiones de los mismos. Por lo tanto, puede decirse que sin responsabilidad social e individual no hay justicia comunitaria.

Las preguntas que guían el siguiente trabajo se enmarcan en el ámbito de la justicia social y la dignidad de la vida en lo individual y comunitario. ¿Cómo es posible pensar la justicia en tanto un derecho humano y la responsabilidad social como un deber? ¿Puede haber justicia sin responsabilidad social? O bien, ¿la responsabilidad social es un modo por el cual el ser humano garantiza la justicia? ¿A qué tipo de igualdad se refiere una justicia social?

El problema de la injusticia social se deriva de un ámbito de desigualdad. Los campos de ésta se enmarcan en la discriminación, la carencia de oportunidades de empleo, el poco acceso a la participación política, el precario servicio de salud y, sobre todo, se presenta en la enorme desigualdad en el reparto de la riqueza.

América Latina, por ejemplo, muestra una enorme desigualdad social en comparación con los países europeos. La desigualdad en una serie de factores básicos para acceder a una vida digna ha traído como consecuencia una serie de problemas sociales, los cuales han reflejado un alto nivel de injusticia, en demérito del reconocimiento de los derechos humanos básicos para toda persona: alimentación, vivienda, salud, etc. En ese sentido Jusidman sostiene que:

En economía de mercado como la mexicana, con un débil sistema de producción social estatal, la desigualdad en los ingresos define los niveles y la calidad de vida de las personas e incluso, debido a la segmentación de los servicios de salud, puede ser determinante en la vida o muerte frente a enfermedades o accidentes (2009, p. 196). 
El ejercicio de la política en México es una muestra de la injusticia social y la irresponsabilidad de sus instituciones ante tal fenómeno. La aparente justicia social se disfraza con la máscara de los programas sociales que aparentan una responsabilidad, la cual, antes que beneficiar la vida digna en las comunidades o sectores sociales: ancianos, niños, mujeres, personas con discapacidad, etc., sólo obstaculizan el desarrollo de las capacidades y/o potencialidades de las personas en detrimento de su formación humana.

De esa manera no se puede sostener que el fin de un programa social sea el foro de la igualdad y la justicia en una sociedad, cuando por principio se ve la enorme desigualdad y posibilidad de vidas diferentes al comparar el salario de un Magistrado del Tribunal Electoral del poder Judicial, que en 2009, oscilaba en cerca de 450,000 pesos mexicanos (mensuales), y el de un obrero u empleado que percibía un salario mínimo de 2000 pesos (mensuales) Jusidman, 2009, p. 196).

Ahora bien, con la aprobación de la Ley General de Instituciones y Procedimiento Electorales se reformó la Ley Orgánica del Poder Judicial de la Federación (publicada el 23 de mayo de 2014, en el Diario Oficial de la Federación), por la cual los Magistrados recibirían, para 2015, la cantidad de 3,738,869 pesos mexicanos, como retribución anual, se pretendió establecer un límite a los salarios de los funcionarios; sin embargo, a pesar de la reforma, las diferencias siguen siendo abismales; la desigualdad en la distribución muestra dos mundos distintos en el reparto de bienes (Domínguez, 2014).

La igualdad disfrazada niega cualquier indicio de responsabilidad social. No se puede hablar de justicia e igualdad cuando la diferencia entre los modos y dignidad de la vida es tan dispar en sociedades como la mexicana. Las oportunidades, amén de ser económicas, deben conducir a toda persona, familia y sector de la sociedad, al establecimiento de formas de vida dignas, en las que puedan asumir y vivir con las condiciones propias de toda persona: sus creencias, costumbres, ideologías, religión, idioma, etc., Jusidman afirma en este sentido que:

No construyen ciudadanía, no desarrollan participación, ni responsabilidad, ni solidaridad. Este tipo de palabras tiende a generar dependencia y a destruir la iniciativa, a fomentar el individualismo y a afectar el tejido social en las comunidades. Son programas de enorme alcance pero de pobre concepción frente a la complejidad de la problemática social del país (2009, p. 204).

En ese sentido: ies ejemplo de justicia un programa social de masas que pretende ofrecer dádivas como paliativos a la desigualdad? La dádiva es peligrosa y, a la vez, mantiene un modo de pensar en la comodidad de la vida: lo poco, seguro. Ahora bien, ipuede entenderse este tipo de apoyos como una 
responsabilidad social? ¿Es posible sostener una responsabilidad en la que el fin se finca en el mantenimiento de la riqueza de algunos cuantos, en una sociedad bajo el control de la dádiva, dirigido hacia los sectores a quienes supuestamente se ayuda? ¿Cómo pensar una igualdad justa y una responsabilidad social como deber humano? Esta es la problemática que da cabida a la siguiente reflexión y análisis a partir de la propuesta del pensador norteamericano Michael Walzer.

En lo siguiente se entenderá por derechos humanos: aquellas prerrogativas inherentes a cada ser humano, como su propia posibilidad de ser, las cuales, antes que ser otorgadas, tiene que ser asumidas y reconocidas de manera recíproca entre las personas que conforman a la especie humana. En ese horizonte, De la Torre, citado por Barba, sostiene que los derechos humanos "Constituyen de modo fundamental al ser humano porque representan 'las aspiraciones y las concretizaciones de justicia' " (1997, p. 16). Asimismo, Barba refiere que es importante resaltar la definición de Hernández y Fuentes de acuerdo con la cual: "los DH son los que la persona tiene por su calidad humana" (16).

Por lo tanto se entiende que los derechos humanos, antes que pertenecer al orden jurídico o social, son un modo originario de ser (Ethos) de toda persona. En ese tenor, son universales en su origen, pero tienden a su peculiaridad social comunitaria e identidad propia en la medida en que se concretizan de acuerdo a las circunstancias del tiempo y espacio vivencial de los pueblos y las interrelaciones sociales.

Debido a que el ser humano se realiza histórica y socioculturalmente en variadas formas concretas y ha ido forjando su valía en la noción y aspiración de los $\mathrm{DH}$, éstos representan una especificidad humana deseada que ha sido creada a su vez en la experiencia, vivida en los límites sociales reales y establecida como jurídicamente positiva (18).

Esto no significa que el concepto de derechos humanos se encuentre en una sola definición. El fenómeno de los derechos humanos (fdh), como se ha dicho, se enmarca en el devenir de sentido de la significación de los pueblos. La especie humana está en una constante transformación, frente a la cual sus posibilidades ontológicas siempre son pensadas de diferentes formas y modos según las interpretaciones del sentido de la experiencia de sus vivencias en el tiempo y el espacio.

Rabossi piensa que no hay fundamentación de los derechos humanos. "El fdh está montado sobre una concepción común respecto de un sistema de valores y de principios de carácter moral. El fdh se funda en esa universalización material y se expresa a través de un sistema normativo de carácter positivo" (1989, p. 333). Si el ser humano es su sustento básico, entonces, el modo de ser de los derechos humanos siempre será un fenómeno universal; sin embargo, cambiante, diferente para cada grupo social. 


\section{Justicia e igualdad social}

De manera matemática la igualdad se resuelve en que $X$ es, en condiciones cuantitativas, igual a $Y$, si y sólo si, ambas poseen la misma cantidad. Eso es igualdad simple. Trasladada a la sociedad eso significaría que a tal persona le debe corresponder la misma cantidad. Todos iguales en todos los sentidos.

Ahora bien: ¿es posible establecer una igualdad simple en una sociedad? Desde el punto de vista de Walzer (2001, p. 9) la igualdad social (simple) como tal no es posible en la medida en que una tal supuesta igualdad tendrá que negarse a sí misma en su intento. La igualdad social sólo es posible en el desarrollo diferente de las capacidades o posibilidades de desarrollo. Eso recuerda que toda igualdad supone la diferencia.

La tarea de la igualdad social consiste en vislumbrar una sociedad libre de dominación: "La dominación siempre es propiciada por un conjunto de bienes sociales dados" (11). Por consiguiente la igualdad significa la no opresión de las personas por esta dominación. La propuesta del autor de Las esferas de la justicia va más allá de lo que considera una justicia e igualdad ideales, haciendo alusión a la propuesta de John Rawls, en el libro Teoría de la justicia. Este trabajo no pretende hacer un análisis del pensamiento de Michael Walzer en comparación con el de Rawls. Ambos, desde su propia perspectiva, presentan dos visiones diferentes del tema de la justicia social y la igualdad; cada postura tiene gran importancia en la visión de la problemática mundial; aquí se analizará el pensamiento de Walzer y, sólo cuando sea necesario, se hará alusión a Rawls.

Walzer entiende por justicia, en general: "un arte de la diferenciación" (2001, p. 13). La igualdad es el resultado de ese arte. La igualdad simple no permite diferenciación; por eso, el autor norteamericano, propone la igualdad compleja como la forma propia en que puede pensarse de manera social: "La igualdad es una compleja relación de personas regulada por los bienes que hacemos, compartamos o intercambiamos entre nosotros; no es una identidad de posesiones" (31).

Los bienes a los que se refiere son de tipo social y se caracterizan por una significación comunitaria, de tal manera que su sentido se encuentra en la interpretación de estos significados; eso permite pensar en una justicia distributiva que dignifique la vida de los seres humanos y no sólo cubra paliativamente una necesidad. Hay que distribuir la justicia de acuerdo a su significación.

El modo propio de ser de la igualdad compleja está en el horizonte de sentido de aquellos a quienes se pretende reconocer tal justicia: 
La igualdad compleja significa que ningún ciudadano ubicado en una esfera o en relación con un bien social determinado puede ser coartado por ubicarse en otra esfera con respecto a un bien distinto...siempre y cuando el cargo no sea un bien dominante, los titulares del cargo estarán en relación de igualdad, o al menos podrán estarlo, con respecto a los hombres y mujeres que gobiernan...Ningún bien social $X$ ha de ser distribuido entre hombre y mujeres que posean algún otro bien $Y$ simplemente porque poseen $Y$ sin tener en cuenta el significado de X (Walzer, 2001, p. 33).

Eso implica que la igualdad compleja, en tanto justicia distributiva, se oponga a un totalitarismo, porque en éste el monopolio de los bienes sociales puede acaparar una o más esferas, hasta la dominación de todas ellas en un grupo social. La posibilidad de una justa distribución estriba en la diferenciación del reparto de bienes. La igualdad compleja es un modo de distribución diferenciado, no desigual, sino diferente.

Una esfera de justicia es el ámbito de relación entre los bienes dominantes y su distribución, de tal manera que se evite un control monopólico absoluto de todas las esferas y, por ende, una clase dominadora que conlleve un sistema desigual (injusto) de distribución. Así, "puesto que si la riqueza, por ejemplo, es dominante y ampliamente compartida, ningún otro bien podría ser monopolizado" (5). En ese tenor no es lo mismo un programa social como dádiva de control, a un reparto justo de la riqueza. Ahora bien, el problema de la igualdad simple radica en que poco a poco crea desigualdades y, por lo tanto, monopolios y predominio de bienes; eso se da en un sistema en donde los programas sociales no alcanzan a llegar a todos los sectores.

Un ejemplo de aspiración a una igualdad simple se dio en México después de la Revolución de 1910. La lucha campesina tenía por objetivo el reparto de tierras, que en ese momento estaban en manos de los hacendados. Grandes latifundios en manos de pocos ricos. El 6 de enero de 1915 se expidió la "ley agraria" con la cual iniciaría el reparto de tierras a los campesinos, pero no fue hasta los años treinta, que se inició durante el gobierno de Lázaro Cárdenas del Río, Presidente de la República de 1934 a 1940. El problema derivado de este reparto fue que, una vez que los campesinos obtuvieron sus tierras, carecían de materias primas para los cultivos, así como de maquinaria. El trabajo rudimentario, la poca producción y el mal pago de sus cosechas los llevó a empeñar o vender las tierras, a muy bajo costo o como pago de deudas a los que antes eran dueños. Al caso, las tierras se perdieron y los nuevos hacendados volvieron a acaparar los dominios territoriales y el control de precios y venta de las cosechas, quedando nuevamente los campesinos como peones mal pagados. Al respecto Adolfo Gilly ha escrito en su libro La revolución interrumpida: 
Las tierras conservadas por los terratenientes no sólo rompieron la unidad de explotación de las haciendas expropiadas en perjuicio de los campesinos y en provecho de los ex propietarios, sino que dejaron a éstos un enclave, un punto de apoyo desde donde volver a asentar su dominación sobre los ejidatarios carentes de instalaciones, de recursos, de créditos, para poder restablecer posteriormente, por muchos canales directos e indirectos, su explotación sobre el campesinado ejidatario (1971, p. 365).

Las esferas de la justicia representan una serie de límites ante cualquier intento de imposición de poder y dominio sobre las otras esferas. Walzer considera que la igualdad de oportunidades sólo será posible en un mundo donde la riqueza, el poder y los cargos políticos tengan límites (2010, p. 123). Por eso cada una de las esferas constituye el margen bajo el que cierto poder de dominio fija sus fronteras, impidiendo imponer el poder sobre otra. En ese horizonte la falta de límites a los dominios del poder ha traído demasiados problemas respecto a la igualdad social en México. Por ejemplo, a los cargos políticos suelen tener acceso sólo aquellos que poseen una cantidad de riqueza económica elevada. A pesar que la democracia permite que todo ciudadano tiene derecho a ser electo: "Poder ser votado para todos los cargos de elección popular, teniendo las calidades que establezca la ley. El derecho de solicitar el registro de candidatos ante la autoridad electoral corresponde a los partidos políticos así como a los ciudadanos que soliciten su registro de manera independiente y cumplan con los requisitos, condiciones y términos que determine la legislación" (Constitución Política de los Estados Unidos Mexicanos, Art. 35, Fr. II), la desigualdad no está en la norma sino en el dominio de la esfera del dinero sobre la participación política.

Walzer propone, frente a la anterior consideración, una igualdad bajo un liberalismo comunitario. A diferencia del liberalismo tradicional donde se destaca la autonomía individual, en el liberalismo comunitario cada esfera resulta de la autonomía colectiva. David Miller, en la introducción al texto de Walzer, considera en ese sentido que:

Así, en lugar de la visión liberal individualista de una sociedad compuesta por individuos autónomos que acuerdan por contrato la formación de instituciones sociales de varios tipos, Walzer ofrece un liberalismo social en el que reconocemos lo mucho que las personas se hallan ya integradas en unos determinados grupos e instituciones, y en el que entendemos la libertad principalmente como la protección de esos entes colectivos frente a la dominación externa (2010, p. 16).

El filósofo de Las esferas de la justica establece una diferencia entre comunidad liberal y comunitarista. La sociedad liberal es la fragmentación de ésta en individuos; por su parte, la comunitarista es coherencia, interconexión y capacidad narrativa (2010, p. 157). Nótese el sentido que el autor norteamericano da a la significación comunitaria, de donde precisamente derivará el significado de igualdad social. 
Rodríguez considera, en ese horizonte, que hay una gran diferencia respecto a la crítica social entre la postura de Walzer y la de Rawls:

Para Walzer, la crítica social sólo puede llevarse a cabo desde la experiencia
misma de la vida social, lo que garantiza su imbricación con los dilemas
reales de la justicia en comunidades específicas, mientras que la filosofía
política se desliga [detach] de las comunidades y, al buscar un punto de
vista imparcial, pierde la posibilidad de "interpretar" los problemas sociales
desde la perspectiva de la comunidad (2010, pp.161-162).

Efectivamente la visión de Walzer implica el modo en cómo la comunidad interpreta el sentido de sus relaciones, de lo cual deriva la forma de distribución de sus bienes y la igualdad social. Se trata del sentido comunitario no de una visión universal, ideal para todos; mientras que Rawls apuesta por una justicia ideal igual para todos los seres humanos.

Aguilar, por su parte, observa que la igualdad, entendida como distribución "desigual", puede ser legítima dentro de una cierta esfera:

Pero un tipo de bien no debería influir sobre otras esferas. Se pueden comprar muchas cosas con el dinero, pero no bienes como la salud o el poder político, cuya distribución obedece a otras reglas, que están en función de su significado social (1999, p.136).

La igualdad, piensa el autor mencionado, está vinculada con el pluralismo:

La igualdad compleja toma en cuenta la diversidad de bienes sociales que se intercambian dentro de una sociedad, cada uno de los cuales constituye por sí una esfera independiente dentro de la cual se establecen los criterios normativos de distribución (143).

Eso significa que el valor de la justicia es el principio universal que rige el carácter de la igualdad, pero esta última sólo es posible, como justicia, en la medida en que permite la pluralidad que mantiene lo justo en cada esfera.

Por otra parte, Socolovsky (1996, p. 29) sostiene la idea, según la cual la igualdad compleja en Walzer se ve justificada por el reconocimiento, en cada esfera, de significación propia, que fija los criterios para la distribución a través de normas y agentes distributivos específicos. Una sociedad libre de dominación es una interrelación de convivencia abierta a la justicia; no como una condición que se otorga, sino en tanto una posibilidad personal y comunitaria que se reconoce.

Walzer piensa al respecto que "la justicia es una construcción humana" (2001, p. 19), esto en la medida en que primero se reconoce como un modo de ser; y segundo, porque sólo es posible, este modo, a partir de su construcción en 
la comunidad y convivencia social. De esa forma la justicia es posible sólo en la diversidad, pues cada grupo, comunidad o sociedad tienen diferentes bienes dominantes y distintas formas de distribución.

\section{Sociedad y justicia}

La sociedad humana puede ser pensada como una serie de interrelaciones de cambio e intercambio de diversos factores, tanto económicos, culturales, salud, educación, riqueza, identidad, pertenencia, políticos, religiosos y de relaciones humanas. "La sociedad humana es una comunidad distributiva [...] los hombres nos asociamos a fin de compartir, dividir e intercambiar" (Walzer, 2001, p. 17). Esto, de antemano, es el resultado de la relación necesaria de convivencia entre las personas en el ámbito humano. Desde ese punto de vista la sociedad es un fenómeno en el cual se trasciende el sentido ontológico de la justicia al hecho social, a la realidad concreta de la comunidad y los problemas y acciones derivados de éstas. La sociedad civil es el ámbito donde se libera una luz de justicia: "La vida asociativa de la sociedad civil es el terreno real donde se elaboran y se prueban todas las versiones del bien...y donde se demuestran parciales, incompletas y, en última instancia, insatisfactorias" (Walzer, 2010, p. 188).

La sociedad civil requiere mostrar el sentido de una "red de asociaciones", bajo la cual sea posible encauzar y mantener una justicia en la comunidad, de tal manera que cualquier tipo de desigualdad se manifieste de manera clara y pueda ser corregida a favor del establecimiento de una igualdad, en la base de las diversas y diferentes necesidades de los grupos. Desde esa perspectiva Walzer considera que una "red de asociaciones libres", debe velar y limitar las funciones del Estado (195). Esta forma de "red" configura el límite a las esferas de bien y distribución, evitando la sobreposición de dominio de unas sobre otras. El intento de una justicia e igualdad, desde un sentido comunitario, estriba en el horizonte de una convivencia ciudadana.

Como afirmó recientemente el expresidente de Uruguay, José Mujíca, en una entrevista con Jordi Évole (2014) "Tenemos que aprender a pensar como especie". En ese tenor, aun siendo contractualista, Rousseau escribió que la perfección del individuo conlleva la decadencia de la especie (2006, p. 75). Walzer afirma al respecto que: "Lo que pone a prueba la sociedad civil es su capacidad para producir ciudadanos cuyos intereses (en ocasiones, al menos) alcanzan más allá de sí mismos y de sus compañeros más inmediatos: ciudadanos que se interesen por la comunidad política que promueve y protege las redes asociativas" (2010, p. 198). 
A diferencia de Walzer, Rawls (1995) propone una teoría de la justicia en la base de un contractualismo. Sin embargo, es importante señalar el carácter cooperativo de su idea de justicia. En ambos pensadores el significado de la justicia tiende al bien de la sociedad, a una convivencia humana en torno a una justicia e igualdad, en beneficio tanto de individuos como de grupos. Rawls refiere textualmente: "En la justicia como imparcialidad, la sociedad es interpretada como una empresa cooperativa para beneficio mutuo" (1995, p. 89). Esto no significa un intento por hacer coincidir ambas posturas. Lo que se pretende es vislumbrar el carácter de la justicia en su sentido social/humano, antes que enmarcarse en una u otra concepción teórica. No basta un individuo justo si su justicia no está dirigida hacia los otros y reconocida en el otro; pero, no es suficiente una justicia comunitaria que margine a las otras personas. En ambos casos se trata de permear la idea de justicia de la comunidad a los más necesitados.

Desde la mirada contractualista, por ejemplo en el pensamiento rousseauniano, puede descubrirse el sentido de una sociedad en su modo originario de reconocer un ideal de justicia. No es lo mismo someter a un pueblo que regir una sociedad (Rousseau, 2007, p. 14). El hombre, dice el autor del Contrato social, pasa del instinto a la justicia: La voz del deber reemplaza el impulso físico, y el derecho el apetito" (21).

La sociedad busca, a través del reconocimiento de la justicia, el bien común: "Los compromisos que nos ligan al cuerpo social sólo son obligatorios porque son mutuos, y su naturaleza es tal que, al cumplirlos, no se puede trabajar para los demás sin trabajar también para uno mismo (34).

\section{Justicia distributiva}

La justicia distributiva, en tanto el arte de diversificar la distribución de los bienes, conlleva el sentido de lo que Platón señala en su idea de justicia: que cada quien haga bien lo que debe hacer, y permita al otro hacer bien su trabajo (1981, 441d-e). La justicia del ojo es ver bien, la del olfato oler adecuadamente; la armonía de las funciones de cada parte del cuerpo establece su justicia, así como el cumplimiento efectivo de cada una de las partes del Estado genera un gobierno justo: el trabajo justo de un pueblo, sumado a la protección justa del ejército, y el trabajo justo de un buen gobierno, hacen posible la justicia en el Estado.

Luis Vives en su texto El socorro de los pobres, refiriéndose a Isócrates, considera que la ayuda al pobre no puede consistir en que el rico se desprenda de todos sus bienes y los reparta por igual entre los pobres (igualdad simple), porque una vez que cada quien tenga lo mismo, peleará por tener más que los otros, y eso provocará violencia, generando nuevos ricos y otros pobres. Lo más inteligente piensa, es que el rico pague de manera justa a los pobres, a través de un empleo digno; así, si cada quien ve satisfechas sus necesidades no querrá quitarle a quien 
le da, sino considerará, más bien, protegerlo para que no pierda su fortuna (Vives, 2007, pp. 75-80).

Distribuir significa dar, asignar, intercambiar. En la distribución se controla el movimiento de los bienes: el poder, el honor, la alimentación, la vivienda, el transporte, la atención médica, la educación, el amor, la riqueza, la seguridad, etc. Los bienes son distribuidos entre sí por las personas, éstas conciben bienes y después los distribuyen (Walzer, 2001, p. 20). Por consiguiente: "La idea de la justicia distributiva guarda relación tanto con el ser y el hacer como con el tener, en la producción tanto en el consumo, con la identidad y el status tanto como con el país, el capital o las posesiones personales" (17).

La justicia distributiva, en la perspectiva de Walzer, implica una distribución compleja, más allá de una distribución simple. No se trata de que a $X$ le corresponda todo $Y$, sino de una posibilidad que requiere cubrir una serie de necesidades marcadas por los diferentes sentidos de los bienes a distribuir en cada sociedad. No consiste en dar a cada persona lo mismo, en algunos resultaría justo, pero para otros sería algo injusto, tanto si no alcanza a cubrir sus necesidades como si no tiene ningún sentido y la ubica en una circunstancia que le da más dominio sobre los demás.

Ejemplo de lo anterior, en la actualidad el gobierno mexicano "premia" con computadoras personales a alumnos tanto del nivel básico como del medio superior y superior; pero, sólo a los más destacados. Resulta injusto el reparto porque, en gran parte, muchos de los beneficiados son alumnos que tiene la posibilidad de comprar uno de tales equipos; en ese sentido, para aquellos que lo tienen resulta insignificante la dádiva; otros, sin embargo, no pueden acceder a la adquisición, pues sus carencias económicas no se los permite; aunado a eso, son estudiantes que no alcanzan el promedio para recibirlo (Véase Convocatoria del Programa Estatal de Excelencia Académica para la obtención de una Computadora Laptop, 2012-2013). Por lo tanto, la distribución resulta desigual, pues no beneficia a quienes lo reciben, y no ayuda a quienes debiera apoyarse. Como este tipo de casos se pueden pensar otros más, en los cuales la distribución, pretendiendo cubrir ciertas carencias sociales, pierde todo sentido de igualdad. Lo mismo sucede con el reparto de becas en todos los sectores educativos: básico, medio superior y superior. Aclaremos que, en lo referente al mérito, éste no será el mejor promedio, pues las condiciones para lograrlo serían al mismo tiempo injustas. El mérito tiene que referirse, en este caso, a la iniciativa de las personas por seguir estudiando, inclusive bajo condiciones inferiores de calidad de vida, en comparación con quienes pueden hacerlo desde una cierta dicha "comodidad" (Walzer, 2001, p. 33). 
La distribución compleja implica un modo de reparto o distribución que tiende a conservarse bajo el reconocimiento de la justicia social. Walzer considera que los bienes deben ser distribuidos en la base de su significado social. Ahora bien, todos los bienes, a nivel mundial, comparten ciertos significados, en los que va el clamor de justicia; sin embargo, "los individuos asumen identidades concretas por la manera en que conciben y crean - y luego poseen y empleanlos bienes sociales" (21). De esa forma como derecho universal debe considerarse que no existe un conjunto de bienes sociales con el mismo significado a nivel global. La distribución justa de los bienes depende del significado social que cada grupo humano, en convivencia, tiene de éstos.

Lo anterior podrá entenderse mejor a partir del texto Moralidad en el ámbito local e internacional (1996). Walzer considera que hay dos tipos de moral, la tenue o minimalista y la densa o maximalista. La primera se refiere al aspecto general que comparten todos los pueblos, culturas o sociedades a nivel global, como especie humana. La justicia en sentido ontológico. Todo ser humano tiende hacia un sentido de justicia, mas la aplicación a las acciones es una cuestión derivada del modo propio de ser del individuo en sociedad. La segunda se refiere a los casos concretos, a lo justo en un determinado entorno social en el tiempo y el espacio, a la circunstancia propia de la experiencia de vida de la comunidad (1996, pp. 33-49).

Asimismo se sostiene, en el mismo escrito, que la justicia distributiva es una moralidad maximalista: "Todo maximalismo se mantiene en una íntima relación descriptivo/crítica respecto de su propia sociedad. Porque lo que expresa en su estilo coloquial, particularista y circunstancial es el idealismo construido por estas gentes. Describe las cosas que hacen, que valoran, que distribuyen entre ellos y las cualidades personales que cultivan y dicen respetar [...]" (1996, p. 71).

Camps retoma la idea de Walzer para hacer referencia a la distribución justa en la esfera de la salud, asunto que permite pensar una cierta perspectiva bioética. En ese tenor señala:

El ejemplo en el que se ha concentrado Walzer para desarrollar su teoría es el de la justicia. En términos generales, ser justo significa dar a cada uno lo suyo, este sería un precepto de una moralidad tenue. En la realidad, sin embargo, la justicia distributiva adopta formas diversas: $<<$ es relativa a los distintos significados sociales $>>$. No es lo mismo distribuir amor, en el seno de la familia, que distribuir educación o distribuir salud. No es lo mismo no sólo porque hay distintas $<<$ esferas de justicia $>>$, sino porque las varias culturas pueden haber entendido y construido de forma diversa el valor de la justicia. Podría parecer que Walzer está defendiendo un relativismo total. Él mismo se encarga de explicar que no es esa su intención. Como decíamos en el capítulo sobre la universalidad de la ética, no todo cabe bajo cada uno de los ideales éticos. No todo cabe o vale bajo el ideal de justicia. 
$\mathrm{Si}$, pongamos por caso, una determinada cultura o comunidad entiende que la mejor forma de distribuir la protección de la salud es eliminando a los mayores de ochenta años más proclives a padecer dolencias, habrá que decir que ese criterio es radicalmente injusto y contrario a la ética. Ese criterio sería rechazado por la moralidad tenue, de mínimos (2005, p. 176).

Los significados sociales y las formas de distribución representan la autonomía de cada esfera de dominio en la justicia distributiva; éstos no deben ser entendidos en términos de jerarquía de poder. De esa manera, el primer bien que se distribuye socialmente es el de la comunidad como esfera determinante del entorno de sentido.

En esa perspectiva, el respeto justo, en una justicia distributiva, se encuentra en la mira del conocimiento de la necesidad y la pertenencia. Walzer sostiene que: "Las mujeres y los hombres que se apropien de grandes sumas de dinero para beneficio personal mientras las necesidades sigan sin ser satisfechas, actúan como tiranos, dominando y deformando la distribución de seguridad y bienestar" (2001, p. 86). Así, por ejemplo, el sistema de programas de ayuda social no siempre se encamina a cubrir las necesidades básicas con un significado real para las comunidades. Suele pasar que la ayuda consiste en bienes cuyos productos benefician cuantitativamente las ganancias de las empresas, aunque el bien social carezca de significado.

La justicia distributiva, mirada desde la perspectiva de las esferas en Walzer, es la interrelación de sentido de los bienes sociales en relación con la necesidad a cubrir. No se logra la justicia distribuyendo un supuesto bien social sin significado y necesidad real. No se trata de distribuir bienes donde no se requieren sino de cubrir necesidades a través de bienes coherentes con la situación real que se pretende atender. "Toda comunidad política debe atender a las necesidades de sus miembros tal y como éstas son colectivamente entendidas por ello; y que la distribución debe reconocer y apoyar la igualdad subyacente a la pertenencia" (94).

La tesis de Walzer, en relación a la justicia distributiva, se concretiza en la frase: "A cada quien sus necesidades socialmente reconocidas" (102). Los seres humanos son iguales en su condición de indeterminación: un ser que se construye siendo, como dice Nicol, es un ser que no tiene forma definida sino que se transforma, es diferente en sus necesidades (1981, p. 5). La universalidad de lo humano se transforma en la diversidad de las necesidades; de ahí que no toda concreción de la justicia sea igual para todos. Sólo en una justicia distributiva de los bienes sociales, basada en las necesidades propias de cada grupo humano o comunidad social, será posible una igualdad compleja. 
Ahora bien: ¿cómo es posible realizar, de manera concreta, una justicia distributiva? Sólo en la medida en que cada esfera de justicia distributiva proteja sus límites y no invada de manera negativa otras esferas. En el caso del dinero, esta esfera no puede ni debe absorber el resto de las otras. Por ejemplo, el dinero que invade otra esfera impide la justicia distributiva, pues condiciona otras como la del poder político o religioso, puesto que a partir de la esfera del dinero se puede comprar y determinar la decisión del voto, o bien, a las instituciones encargadas de proteger los comicios electorales. De igual forma, el dinero puede condicionar ciertos parámetros dentro de la educación y el acceso a los puestos públicos: "El dinero corrompe las distribuciones sin transformarlas y entonces las distribuciones corruptas coexisten con las legítimas, como la prostitución con el amor conyugal" (Walzer, 2001, p. 327).

La justicia distributiva depende de la armonía y el respecto a los límites de las esferas, y la justicia social de la igualdad compleja, en la perspectiva de la distribución de los bienes, bajo un orden y legalidad responsables.

Zubiria comparte el hecho de que no existe un criterio universal y único para la justicia distributiva; por ello, considera que la justicia en cada una de las esferas requiere de criterios diferentes. Al respecto señala: "Los bienes sociales tienen sus propias esferas de operación, ya que tienen significados sociales interpretados por nosotros mismos, que a través de dicha interpretación encontramos acceso a la justicia distributiva con principios internos propios de la naturaleza de cada una de las esferas" (2014, p. 71).

La justicia distributiva es posible en el ámbito de los límites del sentido y significado de cada esfera, como armonía establecida por el significado distributivo de la propia comunidad. De esa manera surge la cuestión en torno a cuál es la condición humana que permita el reconocimiento de dicha justicia. Una posible respuesta es la responsabilidad social como deber humano.

\section{Responsabilidad social}

Thomas Piketty ha escrito en su libro: La economía de las desigualdades, cómo implementar una redistribución justa y eficaz de la riqueza, que se deben atender las condiciones de vida de los menos favorecidos en el reparto de las riquezas a nivel mundial; esto será posible, señala, haciendo extensivos los derechos que se han concedido a unos y no a otros (2015, p.10). Ya no se trata de pensar una justicia social abstracta, sino de asumir una responsabilidad humana frente a tal fenómeno: ante la riqueza desmedida de uno y la pobreza inhumana de otros. 
En un mundo globalizado, piensa Piketty, el equilibrio parece imposible; sin embargo, "las consideraciones de pura justicia social requieren una redistribución desde los individuos menos favorecidos hacia los que lo son más" (11). Estas consideraciones estriban en el hecho de que la esfera de la riqueza (dinero, empresas, etc.), en el orbe mundial, es inequitativa; son pocos los multimillonarios y dueños de la producción de bienes a nivel mundial, en comparación con el resto de la población, quienes, a diferencia, son empleados mal pagados, o bien, consumidores necesarios en pobreza extrema. La inequidad la ejemplifica con el siguiente caso: una persona con preparación en informática genera más como empleado de una empresa (monopolio mundial) si su trabajo genera clientes y consumidores que aumenten la ganancia económica de la compañía; mientras que el policía y el oficinista que archiva la documentación, quienes no generan ganancia, obtendrán un sueldo por debajo de sus expectativas de vida (108-109).

Frente a tal situación cabe preguntar: ¿el valor del ser humano está en ser una máquina de producción de ganancias? ¿Es el desarrollo de una profesión o habilidad técnica lo primordial para una empresa? ¿La empresa mundial que genera riqueza ve en las personas objetos de producción y consumo? Desde este punto se puede cuestionar el carácter de la responsabilidad del ser humano y su sentido en la responsabilidad para con el otro y los otros, así como para todo aquello que implica la vida en general. En términos generales, la responsabilidad es un modo de ser del humano, quien siempre se encuentra proyectado hacia el otro y los otros, de esa manera su responsabilidad es siempre social, porque se encuentra inmersa en un mundo compartido. Por lo tanto la responsabilidad individual y la social se coimplican, de tal manera que no son posibles por separado.

¿En qué consiste la responsabilidad social del Estado y las empresas? ¿Qué hay detrás del disfraz de la responsabilidad social que pregonan las instituciones estatales y las empresas que absorben las riquezas de un pueblo? ¿Hemos olvidado, en ese sentido, pensar la responsabilidad social como una forma del deber de unos para con otros?

Walzer presenta, de manera implícita, ciertos aspectos en relación con el tema de la responsabilidad social. Algunos de sus escritos conllevan una serie de reflexiones en torno al asunto, de tal forma que pueden analizarse desde la responsabilidad social como deber, en tanto una capacidad, potencialidad o virtud humana para reconocer y ejercitar la justicia social distributiva.

Definimos responsabilidad como una relación individual para con el otro y los otros, es decir, ser responsable significa "asumir" las consecuencias por los daños y/o beneficios de las acciones propias hacia los otros. "Asumir" quiere decir: ir más allá de ser conscientes de las acciones u omisiones, significa una relación de identidad humana como especie. Los efectos de las acciones o decisiones construyen o destruyen la formación del ser humano. De ese modo al construir 
con las acciones se preserva la dignidad, la seguridad y el sentido de lo humano; y viceversa, al destruir se daña, tanto la vida personal como la de los otros; esto porque siempre se vive en una sociedad de con-vivencia. Con-vivir es vivir-juntos. La responsabilidad social es, por lo tanto, el cuidado propio que el ser humano "debe" tener por la humanidad y de todo aquello de lo que forma parte: el cosmos (mundo) en general.

Apel considera que la responsabilidad debe velar por los intereses de todos los afectados. El concepto de responsabilidad, en este pensador, gira en torno a una corresponsabilidad solidaria o a una solidaridad de la responsabilidad humana, en la cual no se es importante sólo en lo individual, sino que el género o grupo humano es su propio juez. Textualmente afirma: "La capacidad de lograr consenso de las normas depende, dentro del marco de una ética de la responsabilidad, de la capacidad de lograr consenso de las consecuencias de las normas que hay que aceptar y con ello, en la praxis de la responsabilidad de una predicción suficiente de las consecuencias esperables" (1999, p. 103). Una responsabilidad solidaria surge de un consenso comunitario en la ética; es decir, de una convención ética en la que se toman los derechos de todos los implicados y/o beneficiarios de las acciones humanas.

El ser humano, considera Apel (2007, p. 123), debe "asumir", hoy en día, una responsabilidad global por las consecuencias futuras de sus acciones colectivas. En ese sentido, por las instituciones de las cuales forma parte o suele ser su legitimador. Se trata no de dejar la responsabilidad a las instituciones sino de "asumir" una corresponsabilidad como deber en la solución de todos los problemas. El deber de las instituciones sólo será efectivo en la medida en que el ciudadano cumpla con el deber de exigir a las instituciones trabajar en su esfera y limitar sus atribuciones. Desde la perspectiva de Walzer, los significados sociales "deben ser compartidos por la sociedad, por el grupo de gente que comparte una vida en común, y tal $<<$ compartir > > no puede ser el resultado de una coerción radical" (1996, p. 59).

Asimismo, Walzer plantea, al respecto, la pregunta: "¿Qué se deben unos a otros los ciudadanos en vista de la comunidad donde efectivamente habitan?" (2001, p. 95). En la actualidad se tienen ciudadanos pasivos, cuya función depende totalmente del cobijo de las instituciones; no es la comunidad quien decide la distribución justa de los bienes, sino el mercado industrial en colaboración con las instituciones sociales.

La responsabilidad social se ha encarnado en los directores de las instituciones sociales. El cargo es, por consiguiente, el modo de ejercer la norma y el poder sobre los bienes. Resulta claro, entonces, que la responsabilidad del encargado es el factor propio para generar el reconocimiento y ejercicio de la justicia social, a través de la igualdad distributiva de los bienes. El cargo, dice Walzer, "es tanto una función social como una carrera personal" (166). Por eso no pueden ser 
comprados, ni heredados, mucho menos impuestos por medio de la violencia o la corrupción. Todo cargo que se haya depositado en una persona, a través de estos medios, está condenado a generar violencia; es decir, a causar daño a quienes se hallan involucrados en la esfera que gobierna dicha función social.

Un cargo implica una responsabilidad social, porque beneficia o perjudica a los corresponsables dentro de su esfera. Será una responsabilidad constructiva en tanto que su deber se vea guiado por el respeto de bienes bajo un sentido de justicia; y será responsable y/o irresponsable en la medida que niegue o domine la igualdad distributiva de los bienes, provocando con ello una desigualdad. Walzer señala que: "Antes que un individuo pueda cumplir de manera honorable, debe ser responsable de su rendimiento: tiene que ser un agente moral, el desempeño tiene que ser el suyo" (273). La responsabilidad social, antes que un deber legal, tiene que reconocerse como un modo propio del ser humano. En su carácter de responsable, de rendir cuentas por los daños y/o beneficios de sus acciones, el ser humano se halla ante la dicotomía de actuar de manera responsable o irresponsablemente, frente a sí mismo, al otro y los otros.

La responsabilidad, en su sentido originario (ontológico), conlleva la relación con el otro. Ser responsable sólo es hacia el otro, y en esa medida consigo mismo. "No hay conocimiento del yo sin la ayuda del otro" (Walzer, 2001, p. 283). Eso significa que la distribución de los bienes debe partir de la estima, en tanto una forma de la autoestima y del respeto como un modo del autorrespeto (283).

El autorrespeto sólo es posible en la medida en que se tiene el reconocimiento del otro; no hay autorrespeto cuando no es recíproco con el otro. La posibilidad de asumir la justicia y la igualdad parte de la consideración de una vida en convivencia, en un modo de ser co-mún: con(m)unidad, unidad en la esfera de la relación de sentido. Walzer afirma que "cuando todos los bienes sociales, desde la pertenencia hasta el poder político, son distribuidos por normas justas, entonces las condiciones del autorrespeto serán establecidas de la mejor manera posible" (289).

El autorrespeto es, por lo tanto, pensarse como especie en relación con el otro (el respeto). No es que el "otro" sea mi yo, sino que mi "yo" sólo es posible en el reconocimiento que tengo del otro. El daño y la injusticia al otro es una forma de violencia a sí mismo, porque se dirige a la comunidad y a la especie. Walzer considera en ese sentido que el autorrespeto como autoposesión (poseerse en todas las posibilidades de ser un individuo-humano, con capacidades y potencialidades que generan la relación y el contacto religante con la especie), se da en el carácter de ciudadanía: 


\begin{abstract}
A fin de gozar del autorrespeto, debemos creer que somos capaces de estar a la altura, y tenemos que aceptar la responsabilidad por los autores que constituyen el hecho de estar a la altura o de no estarlo...La ciudadanía es una modalidad de la autoposesión. Nos consideramos a nosotros mismos responsables y somos considerados responsables por nuestros ciudadanos. De esta mutua consideración se derivan la posibilidad del autorrespeto y la del honor público (289).
\end{abstract}

Rawls, por su parte, considera que el respeto a sí mismo o autoestima es un bien primario, quizá el más importante, porque del valor de éste depende lo que se pretende elegir ante cualquier otro bien. En ese tenor considera dos tipos de respeto a sí mismo: 1) el valor de la propia persona que se tiene a sí misma; y, 2) la confianza en la capacidad de la persona para la realización de sus propias intenciones (1995, pp. 398-399). Literalmente señala: "Las condiciones para que las personas se respeten a sí mismas, y unas a las otras, exigirían que sus proyectos comunes fuesen racionales y complementarios: que estimulen sus facultades educadas y que despierten en cada uno un sentimiento de dominio, y que se inserten, en conjunto, en un sólo esquema de actividad que todos puedan apreciar y disfrutar" (399).

Frente a esto, el filósofo de Las esferas de la justicia, sostiene que el autorrespeto del ciudadano coincide con el sujeto ideal de la teoría de la justicia (2001, p. 290). La autonomía del ciudadano abre la puerta a la responsabilidad dentro de la comunidad. En esta perspectiva el ciudadano es activo y crea las condiciones para vigilar y limitar el dominio de los poderes de cada esfera de la justicia: "De manera más general, el ciudadano que se respete no buscará lo que no puede conseguir honorablemente" (290).

Cabe aquí la cuestión acerca de si aquellos que tienen a cargo en las instituciones o empresas la distribución de los bienes lo hacen bajo una igualdad justa y, por lo tanto, representan la responsabilidad y el deber del ciudadano; o más bien, constituyen el obstáculo para la justicia en favor de un grupo o del suyo propio. Las consecuencias de sus acciones derivadas de la acumulación de poder y de la desigualdad en el reparto de bienes conllevan la pérdida de la dignidad de la especie humana. Estos ciudadanos, ciegos al deber de su responsabilidad, son aquellos que otorgan derechos a las personas y comunidades sin asumir el "deber" de cumplirlos.

Bajo el régimen del individualismo la sociedad se percibe como un todo desconectado; desde esa perspectiva la responsabilidad social, en la mira de un autorrespeto, parece imposible. Walzer (2010, p. 107) considera que las relaciones humanas dentro de un grupo crea, desde su sentido originario, un modo propio de ser en una esfera determinada, de tal forma que a tal libertad, dentro de una institución humana, tal igualdad. 
En el libro Pensar políticamente, el autor norteamericano plantea la cuestión: "¿Cómo debemos convivir para no oprimirnos ni hacernos daño mutuamente?" (114). La propuesta consiste en una "red de seguridad" parecida al principio de la diferencia del autor de Teoría de la justica, que dice: "Dando por establecido el marco de las instituciones requeridas por la libertad igual y la justa igualdad de oportunidades, las expectativas más elevadas de quienes están mejor situados son justas si y sólo si funcionan como parte de un esquema que mejora las expectativas de los miembros menos favorecidos de la sociedad" (Rawls, 1995, pp. 80-81).

Se trata de cubrir las necesidades de los más débiles, lo que asegura que los que más tienen procuren cubrir las necesidades de los más débiles, de los que menos tienen, haciendo posible un estado de bienestar de aquellos que requieren de lo mínimo para cubrirlas. Así podrá hablarse de conciudadanos (Walzer, 2010, pp. 120-121). Nótese que se resalta el con, que significa la relación ontológica de la vida de los seres humanos entre sí, con ello se aclara que la ciudadanía es compartida, más allá de haberse reconocido de manera individual.

Lo anterior no pretende establecer una forma de Estado paternalista, que lejos de "asumir" un deber ciudadano, sólo se limite a menguar las necesidades y cubrirlas a medias para proteger las ganancias de los que más tienen. Más bien se trata de un modo de ser solidario del ser humano. La responsabilidad social no puede sostenerse en el dicho que reza: las sobras, para las obras. La responsabilidad del ciudadano, desde su posibilidad de ser con, es un deber ante todo reconocimiento de justica. "La difícil situación de una mujer o de un hombre excluido sigue siendo hoy en día una responsabilidad social y no sólo personal: es responsabilidad nuestra y no sólo suya" (139). La justicia social comienza por la responsabilidad frente a aquellos que han sido excluidos.

La unidad de la comunidad se da en los grupos que conforman su identidad a partir de sus tradiciones, costumbres, idioma, etc. Cuando los individuos no se encuentran en un grupo es el Estado quien acoge tal unidad, pero no es general; de ahí que no sea el Estado la unidad principal de los grupos humanos (18). La responsabilidad social conlleva la unidad del sentido de la convivencia de los grupos; sin esta responsabilidad, ésta queda empeñada al Estado y a los sectores que controlan el dominio de los bienes de distribución.

La propuesta de Walzer en torno a la unidad de la comunidad consiste, no en desaparecer las instituciones, sino en determinarlas, elegirlas y limitarlas mediante una democracia deliberativa y una participación política basada en la ciudadanía, en oposición a una "democracia tradicional". Esta última se caracteriza por ser un modo de imposición no derivado de la unidad de la comunidad. La democracia en la que los votos surgen de un fanatismo, compra o engaño, pierde el carácter de la unidad del sentido de la vida en grupo y responde a intereses de unos cuantos en detrimento de la unidad del grupo. Algunas características de esta 
democracia son, por ejemplo, debatir para exhibir al adversario, negociar votos, hacer campañas, recaudar fondos, etc. (203-204).

La democracia deliberativa tiene que superar el modo en cómo se ha desvirtuado la democracia. En ese horizonte Walzer sostiene: "Por deliberación me refiero aquí a una forma particular de pensar: tranquila, reflexiva, abierta a un gran abanico de pruebas y evidencias, respetuosa con las diferentes opiniones" (204). El modo de ser de la democracia deliberativa se abre al sentido de la comunidad en la medida en que se piensa desde las necesidades del grupo, más allá del interés particular.

Una comunidad es conducida a participar en una democracia tradicional a través de la movilización de intereses individuales o pasiones; de eso se encarga el sistema cuando se trata de legitimar el carácter oficial de las elecciones. La obligación de votar, en una democracia tradicional, nada tiene que ver con el deber del voto, puesto que éste implica el sentido de relación y convivencia con el otro y los otros. No es sólo "mi" bien, sino responsablemente el bien de la comunidad. Por eso al referir una democracia deliberativa, ésta va más allá de ser un instrumento de intereses de algunos en detrimento de otros. El sentido de la democracia deliberativa está orientado hacia el bien común; en la democracia deliberativa se encuentra el deber de velar por una sociedad justa: "Los ciudadanos y las ciudadanas se defienden unos a otros y defienden su vida en común; el gobierno no es más que el instrumento del que disponen" (309). Apremiar por el sentido originario de la comunidad, de la unidad en común, donde se encuentra el sentido de la responsabilidad social como deber: "Es lo que ustedes son, no lo que hacen, lo que los convierte en vulnerables: en la identidad está la responsabilidad" (375).

Socolovsky, en contraposición al planteamiento walzeriano, considera que el ciudadano del autorrespeto, el virtuoso, no deja de ser un ciudadano autointeresado (1996, p. 10). Textualmente dice: "Sencillamente el otro no existe. Y esto es así porque Walzer subordina todo reconocimiento de derechos a decisiones distributivas previas, las cuales dependen de los significados sociales de los bienes que, al igual que estos significados, son internos a la comunidad" (11).

La autora se refiere a aquellos que quedan marginados del significado social de los bienes. Sin embargo, el planteamiento de Walzer siempre busca que estos "marginados" sean considerados, de alguna manera por los significados de distribución. Eso por un parte reviste garantía al grupo social dentro de un significado y respecto por la dignidad del otro. De ninguna manera podría excluirse a los otros que en origen no están dentro del significado social. La responsabilidad social, como deber, implica no sólo el reconocimiento del grupo, sino también la visión hacia aquel que puede integrarse al grupo. La identidad individual se da al mismo tiempo que la comunitaria. No pueden pensarse por separado, sólo 
son posibles en que ambas, al mismo tiempo, se codeterminan. De ahí que la responsabilidad individual sea la misma responsabilidad social.

\section{Justicia como derecho humano y responsabilidad social en tanto deber}

Las personas viven en grupos sociales dentro de un sistema de significados sociales, lo cual da sentido a cierta objetividad. Walzer considera que las normas sociales de conducta (la legislación moral), en su origen, son fruto del significado social. Los objetos adquieren valor en la medida en que están inmersos en un entorno de sentido: "Los significado sociales son construcciones de objetos realizadas por conjuntos de sujetos, y en cuanto tales construcciones se implantan, por así decirlo, la comprensión del objeto pasa a estar determinada (y seguirá estando determinada) por los sujetos" (2010, p. 75).

La moral derivada del significado social no es relativa, porque no es una moral "decidida", elegida de manera instrumental por una institución o grupo de poder determinado; es producto de una construcción social de objetos, en este caso normas. En ese sentido, la norma, conforme a Derecho, no sólo se otorga, sino que se reconoce como un modo de ser de la comunidad. Ésta reconoce el derecho humano a la justicia, en tanto su propio sentido de ser; $y$, como deber, al mismo tiempo, bajo la responsabilidad social.

Walzer piensa que algunas construcciones de significado social podrían ser parecidas o iguales en diferentes culturas, esto porque puede coincidir que los seres humanos o grupos sociales interpreten desde un punto de vista general la misma situación vivencial en el mundo, respecto al valor de un hecho o un objeto (82-83). Eso no significa que las mismas construcciones de significado social se deriven del mismo modo, es decir, las circunstancias de interpretación pueden ser diferentes respecto al mismo valor que se le da a un objeto.

El derecho a la justicia es universal (moralidad tenue) para cada grupo humano; en su propio modo de vida (moral densa) tiene una forma de ser propia, de acuerdo al significado de su experiencia vivencial, es decir, en el significado de la distribución de sus bienes. Todo ser humano se alimenta (derecho humano), pero cada grupo humano tiene su modo propio de hacerlo (el deber de cada grupo es proporcionarlo). La justicia estriba en que, como derecho humano, se tenga como un bien básico o primario a cubrir, no por dádiva o compasión, sino en la responsabilidad de los miembros del grupo. No se trata sólo de cubrir la necesidad, sino de dignificar el modo en cómo se reconoce este derecho. Walzer piensa que en toda esfera social de construcción de significado es posible un derecho del ser humano a no ser tratado como objeto de uso. 
A diferencia de los derechos individuales, Walzer trata el asunto de los derechos comunitarios. Uno de ellos es la tolerancia en referencia a las diferencias culturales, religiosas, y a los modos de vida de los grupos. Al respecto señala: "La justicia parece tener un carácter universal por la misma razón por la que la autonomía y la adhesión son reiterativas: por el reconocimiento y el respeto que inspiran los agentes humanos que crean el mundo moral y que acaban teniendo, en virtud de esa creatividad, vidas y países propios" (2010, p. 275). Lo común de los seres humanos es el poder creativo, los logros son una forma de esa construcción, pero tienen un trasfondo de orden ontológico en cuanto responden a una forma de ser propia de lo humano; es decir, hay una justicia y una responsabilidad como Ethos de lo humano, los cuales, en la construcción de su diversidad y su autonomía se concretizan en un derecho a reconocer y un deber a asumir.

Walzer sostiene que los derechos humanos son creaciones humanas relacionales, no pertenecen a un solo individuo; las posibilidades de éste son viables en la medida en que se encuentran en relación con los otros. Por eso, a la justicia se le reconoce como un derecho y a la responsabilidad social ante ésta, un deber. Así en la medida en que se es responsable para con el otro se amerita el reconocimiento de la justicia comunitaria. En ese sentido, los derechos humanos siempre tienen que ser positivos. Un derecho negativo es una acción indirecta (derecho a que no me maten, derecho a la alimentación), mientras que el derecho positivo refiere una acción indirecta, no pasiva, sino creativa (proteger al otro para que no se le dañe, proporcionar el modo para que las personas tengan una forma de subsistencia acorde con el sentido de su vida) (357).

Por lo tanto, el reconocimiento de los derechos humanos implica el deber de aquellos que lo reconocen. No hay derecho humano sin un deber que reconozca el sentido humano y originario de éste. Sólo en la medida en que se asume la responsabilidad social del deber se podrá acceder a la justicia como derecho. En el caso de México, la Constitución de 1917 otorgó en sus primeros artículos las garantías individuales, pero el deber de asumir su cumplimiento quedó a expensas de las instituciones del Estado, lo cual se desarrolló de una manera poco responsable, obstaculizando a los ciudadanos la igualdad en la justicia. Al respecto Zapata, en su texto: "Los derechos humanos en la Constitución mexicana. Una visión histórica", refiere:

En efecto, el artículo primero del texto constitucional fue cambiado de manera sustancial, pues tanto la Constitución de 1857 reconocía los derechos del hombre como anteriores al estado, dejando a la norma jurídica la manera de protegerlos y garantizar su ejercicio, sin duda, bajo la concepción iusnaturalista, la de 1917 lleva una tendencia positivista y deja a la Carta Magna el otorgamiento de la garantías establecidas en la Constitución. Daban por hecho que de manera expresa o de forma implícita 
la Carta Fundamental los contemplaba y por consecuencia eran inherentes a ella; por lo tanto, contenía todos los derechos del hombre y la prioridad era abocarse a su protección (Abreu y Le Clercq, 2011, p. 97).

En el año 2011, estas garantías se transformaron en el reconocimiento como derechos humanos. El 10 de junio se publicó el decreto y al día siguiente entró en vigor (13)

Ahora bien no basta con que se reconozcan bajo el trasfondo de la justicia e igualdad sociales, es necesario que las instituciones y las personas asuman la concreción, el ejercicio o cumplimiento de tales derechos como un deber de la responsabilidad social. Zapata sostiene, entorno al cambio de garantías a derechos que: "no se limita únicamente a un cambio en la redacción sino a una transformación conceptual. Se entiende como derechos naturales inherentes por el hecho de ser persona y por lo tanto anteriores al estado, y en consecuencia deben reconocerse y protegerse" (104).

No se trata de desaparecer las instituciones sociales sino de construirlas de manera crítica, de tal manera que su función siempre esté bajo el sentido de la responsabilidad social como deber propio de su función; y que por supuesto, dicha función se limite a su propio quehacer sin intervenir en otras esferas a las cuales pudiese dañar en su función.

\section{Reflexión final}

La justicia en el reparto de bienes sólo es posible en la responsabilidad social como deber. Ser responsable es el modo por el cual se "asumen" las consecuencias de los actos, a partir del motor del deber que impulsa a mirar al otro y los otros como uno mismo en la perspectiva de vida.

La justicia distributiva tiene su fundamento en la igualdad compleja. En México se tiende a la igualdad simple por razones políticas y empresariales; esto ha traído consecuencias de una enorme desigualdad social en todos los ámbitos: reparto de riqueza, empleo, salud, educación, etc. Eso significa que no se ha actuado desde una visión crítica de las condiciones de vida del grupo. La responsabilidad social no ha sido cuestionada desde la perspectiva del deber; éste no ha permeado el sentido comunitario de las acciones humanas. Por consiguiente la responsabilidad social por el cuidado de la comunidad se ha disfrazado a favor de acciones e intereses particulares de uno o algunos individuos del grupo, creando, a la vez, un sentido de individualidad en los ciudadanos, quienes se muestran extraños entre sí, olvidando pensarse como especie o comunidad humana. 
En ese sentido la justicia requiere ser reconocida como un derecho humano. La vida en sociedad conlleva el modo propio de lo justo en comunidad; pero esto sólo será posible si se complementa con una responsabilidad social en tanto un deber. No hay justicia si al lado no hay un deber. Si las instituciones, políticas y acciones de las empresas no parten del deber de asumir acciones en favor del grupo, no es posible que un grupo funcione como tal.

La propuesta de Walzer es un hito en la filosofía política contemporánea, un faro orientador que invita a pensar, en este caso para México, un modo de entender y poner en práctica la política desde la justicia como un derecho humano y la responsabilidad social en tanto deber. El paradigma del individualismo es el núcleo germinal de la corrupción. Mientras no se aprenda a pensar como especie o grupo, las acciones humanas no podrán asumir el sentido de la justicia y la responsabilidad $\varphi$

\section{REFERENCIAS}

Abreu Sacramento, J.P. y Le Clercq, J.A. (Coords.), (2011). La reforma humanista. Derechos humanos y cambio constitucional en México. México: Porrúa.

Aguilar Sahagún, L.A. (1999). "La teoría de la justicia de Michael Walzer frente a los retos del pluralismo y la igualdad educativa en México". Revista Latinoamericana de Estudios Educativos, XXIX, 133-150.

Apel, K.O. (1999). Estudios éticos. México: Fontamara.

Apel, K.O. (2007). La globalización y una ética de la responsabilidad. Buenos Aires: Prometeo.

Barba, J. B. (1997). Educación para los derechos humanos. México: F.C.E.

Camps, V. (2005). La voluntad de vivir. Barcelona: Ariel.

Gilly, A. (1971). La revolución interrumpida. México: Ediciones el Caballito.

Nicol, E. (1981). La agonía de Proteo. México: UNAM.

Piketty, T. (2015). La economía de las desigualdades. México: Siglo XXI editores.

Platón (1981). La república. Madrid: Gredos. 
Rabossi, E. (1989). "El fenómeno de los derechos humanos y la posibilidad de un nuevo paradigma teórico". Revista del centro de estudios Constitucionales, (3), 323-343.

Rawls, J. (1995). Teoría de la justicia. México: F.C.E.

Rodríguez Zepeda, J. (2010). El igualitarismo liberal de John Rawls. Estudio de la Teoría de la justicia. México: Porrúa-UAM.

Rousseau, J. J. (2006). Discursos sobre el origen y los fundamentos de la desigualdad entre los hombres. Buenos Aires: Claridad.

Rousseau, J. J. (2007). El contrato social o principios de derecho político. Madrid: Tecnos.

Socolovsky, M.Y. (1996). "La comunidad excluyente: Crítica de la teoría de las esferas de justicia de Michael Walzer". Revista de Filosofía y Teoría Política, (3132), 295-311.

Vives, J.L. (2007). El socorro de los pobres. Madrid: Tecnos.

Walzer, M. (1996). Moralidad en el ámbito local e internacional. Madrid: Alianza.

Walzer, M. (2001). Las esferas de la justicia. México: F.C.E.

Walzer, M. (2010). Pensar políticamente. Madrid: Paidós.

Zapata Perogordo, A. (2011). "Los derechos humanos en la Constitución mexicana. una visión histórica". En J. Abreu Sacramento y J. Le Clercq (Coords.), La reforma humanista. Derechos humanos y cambio constitucional en México. México: Porrúa.

Zubiria Mutis, B. (2014). "Renta Básica y Estado Plurinominal: opciones para la justicia global. Una reflexión desde las esferas de la justicia de Michael Walzer". Eidos, (21), 64-84.

\section{CIBERGRAFÍA}

Constitución Política de los Estados Unidos Mexicanos. Recuperado de http:// www.diputados.gob.mx/LeyesBiblio/htm/1.htm.

Convocatoria del Programa Estatal de Excelencia Académica para la obtención de una Computadora Laptop. Gobierno del Estado de México. Plan de Desarrollo del 
Estado de México 2012-2017. Recuperado de www.ipomex.org.mx/ipo/archivos/ downloadAttach/100769.web

Domínguez, A. (2014). “¿Qué prestaciones tiene un magistrado electoral? Tomado de Milenio.com. Recuperado de http://www.milenio.com/politica/Magistrados electorales-TEPJF-prestaciones_tribunal_electoral-prestaciones_magistrados_ electorales-pension_de_retiro-pension_vitalicia-haber_de_retiro_0_302369949. html.

Évole, J. (2014). "Pepe Mujica, camino de vuelta". " Salvados, temporada 8, capítulo XII. Recuperado de http://www.atresplayer.com/television/programas/ salvados/temporada-8/capitulo-12-entrevista-jos-mujica_2014051600360. html\#fn_sinopsis_lay

Jusidman, C. (2009). "Desigualdad y política social en México". Revista Nueva Sociedad, (229), 190-206. Recuperado de http://nuso.org/articulo/desigualdad-ypolitica-social-en-mexico/ 